\title{
Formulação do Planejamento Econômico-Social
}

\author{
Dicamor Moraes
}

\begin{abstract}
A
ciência da administração, entre outros méritos, dá ao dirigente essa tão necessária noção de segurança no tratamento dos negócios que tem de enfrentar, em proveito da emprêsa e da coletividade a que o mesmo está vinculado pelos laços do interêsse material ou social. Apoiado em elementos que a moderna tecnologia administrativa the pode assegurar, o dirigente da atualidade está convenientemente habilitado a levar a bom têrmo a tarefa que a si se impõe ou se lhe delega. Não mais lhe é dado alegar deficiência de recursos técnicos.

A fase das improvisações empíricas já está plenamente superada, por isso que, dentre as funções administrativas, o planejamento ocupa lugar saliente. Dêle depende grande parte do êxito de determinado programa a realizar.
\end{abstract}

\section{PRAZOS E FASES DO PLANEJAMENTO}

Ėm boa sistemática, "administrar é prever, organizar, dirigir, coordenar, controlar" (FAYOL). Ai figura, em primeiro plano, a idéia de planejamento - indispensável como norma de conduta até mesmo nos cometimentos de caráter pessoal. Ao definir essa norma de ação, com simplicidade e numa sintese feliz, JoHN VIEG diz que "planejar é ir ao encontro do porvir, para modelá-lo segundo nossos desejos".

O porvir, aí, pode ser encarado tanto como futuro imediato, como por um periodo a longo prazo. Obrigatòriamente, lança-se măo do orçamento anual para as previsões a curto prazo. E' o recurso utilizado para o atendimento das necessidades normais da ennprêsa pública ou privada. Já em relação aos problemas de maior envergadura - aquêles que são a soma de problemas me- 
nores - sòmente mediante a elaboração de planos a longo prazo é que se consegue chegar a resultados satisfatórios. Os dois planos - o de curto e o a longo prazo - não se repelem. Antes até se completam, figurando, porém, o orçamento anual como etapa do planejamento a longo prazo.

Tanto para o plano a curto prazo como para o de longo prazo, aplica-se a definição de pi @gramas de ação administrativa expressos em têrmos de dinheiro. Em ambos planeja-se o programa e planeja-se a ação. São duas fases bem caracteristicas.

O planejamento do programa surge como um imperativo para a solução de determinados problemas econômicos e sociais. Ao equacioná-los, cabe ao administrador estabelecer uma hierarquia dos niesmos, tendo em vista:

a) o grau de urgência ou de necessidade com que a solução do problema é encarada;

b) a vinculação de um problema a outros, a fim de que o tratamento dispensado aos mesmos não provoque colisões.

Ilustrando: o abastecimento dos grandes centros consumidores apresenta-se como uma imperiosa necessidade de ordem social. Mas para que se obtenha uma solução racional dêsse problema, inpõe-se programar, também, o fomento da produção e a. melhoria dos meios de transporte, dada a intima conexão existente entre estas atividades e a questão apresentada.

Essa fase do planejamento requer uma análise percuciente da situação econômico-social, com base em dados estatísticos e conjunturais. Escolhidos os problemas que vâo ser objeto de solução, levantam-se as premissas, e leva-se em conta a observância aos princípios compatíveis com a sistemática do planejamento.

Planejamento da ação é a fase requerida no instante em que se cogita da instrumentalização indispensável à execução do programa. Nesse momento planeja-se o recrutamento do pessoal e a aquisição do material necessários à implantação do sistema; promove-se o levantamento dos recursos destinados ao financiamento do empreendimento; elabora-se o orçamento, enfim.

Dispondo dêsses elementos, está o administrador em condições de formular o plano em tôdas suas etapas. São os elementos que integram as atividades-meios do Estado e de cuja manipulação depende o bom ou mau sucesso do empreendimento visado. Tenha-se sempre presente que a fixação de responsabilidades está condicionada a que tudo esteja bem pesado, medido e contado. $\mathrm{E}^{\prime}$ o respeito à metodização.

Tanto no planejamento do programa como no planejamento da ação, cabe ao Estado traçar as diretrizes, em consonância, 
naturaimente, com as necessidades e solicitação da comunidade a que serve. E' certo que as instituições locais dispõem de organização para satisfazer suas próprias necessidades de caráter econômico e social, através de seu mecanismo agrário, industrial e comercial, de seus institutos educacionais, sanitários e previdenciários. Mas há problemas que, pela sua amplitude, transcendem os limites das comunidades locais, para adquirirem caráter regional e nacional. Entre outros, basta a citação dos relacionados com as grandes vias de comunicação e a produção de energia, aos quais estão subordinados o sistema de abastecimento e a produção de bens e utilidades.

Sòmente à administração nacional e estadual, com sua capacidade de coordenação conforme a questão se apresenta, incumbe dar a solução de ordem geral e não apenas local para problemas como êsses e outros que tais. Ainda há os que vêem no planejamento estatal "um procedimento antidemocrático; que há, nesse processo, imposição de tarefas do alto para baixo, o que tiraria todo o poder de participação e expressão aos que se situam nos niveis inferiores, e tornaria o planejamento incompativel com o federalismo ou a autonomia municipal, por exemplo. Nada mais falso, entretanto. O principal objetivo do planejamento é promo ver coordenação, que deve resultar das técnicas de condicionamento das ações isoladas, para dar-lhes unidade, mas que também exige cooperação, que é uma atitude mental - desejo de unir esforços visando ao bem comum" (Newton Ramalho, in "Aspectos Técnicos do Planejamento").

\section{PRINCÍPIOS QUE REGEM O PLANEJAMENTO}

A elaboração do plano econômico-social requer um procedimento sistematizado, em que se consubstanciem critérios analíticos para a identificação de princípios normativos e de metodização adequada. O respeito a essa disciplinação de trabalho dá foros de ciência ao sistema do planejamento.

$\mathrm{Na}$ formulação do planejamento, cumpre levar em conta a observância a certos princípios normativos, sem o que se corre o risco de ver desfigurado o empreendimento que se objetiva realizar. São êles: a exatidão, a unidade, a continuidade, a flexibilidade, a aceitabilidade, a clareza, a exeqüibilidade.

Exatidão - Não se concebe a elaboração de qualquer plano sem a conveniente fundamentação à base de elementos exatos pelo que ae verdadeiro encerram. Deve o planejador munir-se de informes seguros provenientes de levantamentos estatísticos e conjunturais. Não dissociar a estatistica da conjuntura, porque às 
vêzes aquela pode ser objeto de correção por esta. Caso típico é o do crescente aumento de determinada produção agrícola, conforme provam os dados estatísticos, aumento êsse passivel de ser, a qualquer momento, comprometido por um motivo fortuito e imprevisivel, v.g. uma praga, um fenômeno climático, uma revolıção ou guerra.

Unidade - E' admissivel a subdivisão de um plano em setores, desde que êstes se entrosem entre si. O que não se admite é a coexistência de planos diferentes para atingir idêntico propósito. Se se objetiva, por exemplo, aumentar os índices da produção industrial, seria uma incoerência planejar a redução tarifária de importação de produtos similares aos da fabricação nacional. Outra incoerência, por omissão unilateral, seria a produção de fomento agrícola em determinada região, sem lhe facultar os meios de escoamento fácil através de estradas.

Continuidade - Tudo deve ser planejado de modo a evitar uma possivel e quase sempre desastrosa interrupção do plano. Para isso, é preciso considerar a interveniência de certos fatôres, entre êles:

19) O limite da capacidade da perspicácia humana, o qual varia segundo o grau do objetivo a atingir. Se se trata de fazer face às despesas normais da administração, basta prever os quantitativos tributários anualmente arrecadados (orçamentos anuais); mas se se conceber a realização de empreendimentos que excedem as medidas comumente adotadas nos orçamentos anuais, aí então cabe recorrer ao plano plurienal, de duração limitada à capacidade de mensuração dos elementos de que se dispõe no momento.

2.) A oposição de grupos interessados em desvirtuar as diretrizes programadas. Para que isso seja evitado, cumpre assegurar completa independência de ação aos elementos designados para a composição do órgão planejador.

Flexibilidade - Consiste êste principio na necessidade de amoldar-se o plano às circunstâncias ocorrentes seja por inovações, seja por imprevistos. Embora seja respeitada a estrutura original do plano, êste deve ter flexibilidade bastante para ser revisto e alterado face à ocorrência de fatôres contingenciais produzidos por injunções econômicas e sociais. Inovações, principalmente as de ordem técnica; imprevisto, em especial os resultantes de fatôres relacionados com a produção e com novas exigências sociais - são elementos que não podem ser desprezados pela ação planejadora. Esta sentirá logo a necessidade de adotar nova estratégia, segundo a fôrça com que se declaram os elementos assinaiados. 
Aceitabilidade - E' imprescindivel a auscultação à opinião pública e politica a respeito dos problemas equacionados e objeto de planejamento, a fim de obter aceitação franca e expontânea das camadas que formam aquela opinião. Não perder de vista, portanto, as aspirações naturais do povo manifestadas através da imprensa, e a ponderável fôrça política do Parlamento onde o plano deverá ser aprovado ou vetado.

Clareza - O respeito à soberania popular exige que se deva satisfação dos atos governamentais, expressos através de diretivas politicas e econômicas. E como estas últimas são tornadas públicas sob a égide de complexas ciências como economia e finanças, impõe-se apresentá-las, tanto quanto possível, de maneira simples e clara, a fim de torná-las inteligiveis pelo menos ao cidadão de cultura média. Um plano acompanhado de quadros comparativos e de gráficos demonstrativos da situação econômico-financeira, possibilitará maior receptividade, porque tornará mais acessivel sua leitura e análise.

Exeqüibilidade - Há um mínimo de condições cuja observância possibilitará a implantação e conseqüente sucesso do empreendimento planejado. São condições consubstanciadas no que intitulamos de capacidade tridimensional: capacidade da mão-deobra, capacidade físico geográfica, capacidade financeira. Em outras palavras: na formulação do planejamento econômico-social, cumpre observar se há mercados acessiveis para o abastecimento da mão-de-obra indispensável; se o meio físico-geográfico pode atender às solicitações programadas para a produção agrária e industrial; até quando suportarão as fontes de renda os saques destinados ao financiamento dos projetos.

A exemplo da proposição feita por LuTHer GuLICK em relação aos princípios que devem nortear a Ciência da Administração, desejo fique aqui consignada proposição idêntica no tocante aos princípios sob os quais se rege o processo do planejamento. Trata-se de um recurso didático destinado a facilitar a memorização dos princípios ora enunciados.

Gulick, co-autor do livro "Papers on the Science of Administration" (New York, 1937), lançou a sigla POSDCORB, a titulo de auxiliar mnemônico dos princípios a que todo administrador deve obediência, se quiser dar cunho racional às tarefas que 
The são impostas em sua atividade profissional. Descompondo-se POSDCORB, tem-se:
Planning
Organizing
- Planejamento
Staffing
Directing
Coordinating
Reporting
Budgeting
- Organização
- Administração do pessoal
- Direção
- Coordenação
- Informação
- Elaboração orçamentária

Com o mesmo objetivo, e lançando mão de idêntica formação acróstica, proponho a sigla EUCFACE para sintetizar os princípios do planejamento, a qual assim se decompõe:

Em português

Exatidão

Unidade

Continuidade

Flexibilidade

Aceitabilidade

Clareza

Exeqüibilidade
Em francês

- Exactitude

- Unité

- Continuité

- Flexibilité

- Approbation

- Clarté

- Exécutabilité (neologismo)

\section{METODIZAÇÃO DO PLANEJAMENTO}

Principios normativos e metodização adequada, são as bases que informam o procedimento sistematizado a que deve obedecer a elaboração do plano econômico-social. (Os Princípios foram focalizados na publicação anterior).

Uma vez equacionados os problemas econômico-sociais através do que se convencionou chamar de planejamento do programa, segue-se a fase de trabalho em que se procuram os meios necessários à execução do programa. Urge, então, aparelhar-se com a instrumentalização apropriada, para que se concretize o "modus faciendi". E' a fase do planejamento da ação, em que se provêm o recrutamento do pessoal e da aquisição do material, os recursos e gastos financeiros. Urge, sobretudo, impor método ao trabalho em questão.

Nesse pressuposto, a formulação do planejamento, na aludida fase, deve subordinar-se a uma processualística tôda especial. A 
começar pela fixação dos objetivos a atingir, prazo de duração do plano, caráter do órgão planejador, até os requisitos exigidos do pessoal responsável pela sua estruturação.

A fixação dos objetivos a atingir requer uma tomada de consciência da situação econômico-social da entidade sob planejamento. Situação que deve ser analisada segundo a mesma ordenação do processo clínico a que o médico submete seu cliente: exame, diagnóstico, terapêutica. Exame com fundamento em análises dos mais importantes setores de atividades econômicas e das ma1s sentidas necessidade sociais. Análises cujo reativos são os elementos fornecidos pela Estatística e pelos relatórios acusadores de deficiências. Êsse exame analítico permite um diagnóstico nıais seguro da situação econômico-social, de vez que afloram, perfeitamente configurados, as causas e os efeitos das deficiências econômicas que incidem sôbre o organismo social. Diante dêsses resultados, fica-se melhor habilitado a traçar a terapêutica a seguir, isto é, a estabelecer o plano de ação instaurador do equilibrio funcional da entidade de que se cuida.

A adoção dêsse método de trabalho implica no respeito a certos princípios que regem o planejamento econômico-social. Assim é que se deve ter sempre presente: a exatidão dos elementos estatísticos e conjunturais, para evitar que a previsão sofra distorções desfiguradoras do plano; a unidade de ação, mediante a implantação de um plano isento de incoerências no tocante ao tratamento de problemas que entre si colidam; a preocupação em manter-se a contintidade do plano, tendo em vista a resistência oferecida pelo público ou por grupos poderosos, no tocante à duração e às diretrizes da ação programada; a flexibilidade exigida face às inovações e imprevistos que podem surgir e contribuir para a desfiguração do plano; a aceitabilidade, pela opinião pública e política, dos objetivos que se tem em vista atingir, porque, sem o apoio dos órgãcs representativos daquelas vozes (imprensa e parlamento), estará o sucesso do plano comprometido; a clareza na apresentação formal do plano, de maneira a torná-lo mais inteligivel em relação à sua leitura e análise; a exeqüibilidade das realizações programadas, com base na capacidade tridimensional assim representada: mercado de trabalho acessivel ao abastecimento da mão-de-obra necessária, meio físicogeográfico compatível com a produção agrária e industrial, grau de suportação das fontes de renda para fins de financiamento dos projetos.

O prazo de duração do plano deve ser fixado tendo-se em vista a realização de um programa de ação exeqüivel tanto quanto as perspectivas assim o autorizem, com base nos elementos pes quisados. Está ai evidenciado o cumprimento aos princípios da 
exeqüibilidade e da exatidão. Cinco, seis, sete e até dez anos sã: os períodos geralmente considerados suficientes para a obtenção dos resultados previsiveis, levando-se em conta o limite de capacidade da perspicácia humana. Estaria, assim, garantida a continuidade da ação planejada (mais um principio respeitado).

Maior prazo do que êsses implicaria em superestimar a capacidade previsora, sabido que injunções de várias ordens podem alterar as situações previstas. Por isto mesmo é aconselhável a reformulação do plano cada ano transcorrido de sua execução. Trata-se de procedimento fundamentado no principio da flexibiliclade, que consiste na necessidade de amoldar-se o plano às circunstâncias ocorrentes, seja por inovações de ordem técnica, seja por imprevistos resultados de fatôres relacionados com a produção e com novas exigências sociais.

Se a reformulação periódica é imprescindivel, então por que não se satisfazer com o orçamento anual, que é também um plano de ação governamental expresso em têrmos de dinheiro?! Pela simples razão de que o orçamento anual, por sua curta duração, não permite uma visão mais larga sôbre as tendências da evolução econômico-social. O orçamento anual figura, isto sim, como uma etapa do plano a longo prazo.

O caráter do órgão planejador - Condição essencial para o bom êxito da formulação do plano é a escolha do tipo de organização a que se deve atribuir a função do planejamento. $O$ órgão planejador deve apresentar certos característicos institucionais que o habilitem a levar a bom têrmo a tarefa ao mesmo imposta. Dentre outros, salientam-se na esfera estatal:

I - A direção do Órgão deve ser integrada por autênticos técnicos em planejamento econômico-social, por estar subentendido serem êles mais familiarizados com os fenômenos e os elementos que informam a infra e a superestrutura do organismo estatal. Idêntico conhecimento não pode ser exigido de profissionais especializados em arquitetura, engenharia, medicina, educação, segurança e em atividades mercantis, porque isso implicaria, conforme observa MuÑoz Amato (in "Introduccion a la Administración Pública"), em tomar o acessório pelo principal. Claro que o assessoramento dêsses técnicos é imprescindivel para o fornecimento de dados exatos em relação a cada uma de suas especialidades. Mas é ao técnico em planejamento a quem deve competir, após presumir-se dos elementos informativos fornecidos pelos citados especialistas, o disciplinamento do material destinado à elaboração do plano geral.

Donde concluir-se ser o aludido tipo de direção - a dos técnicos em planejamento - mais racional do que o da forma colegiada em que participem técnicos especializados nos vários 
ramos do conhecimento humano. Sob êste último tipo é comum verificar-se a deformação do planejamento, porque a natural vaidade profissional determina inevitáveis choques em tôrno da prevalência ou da hierarquia de tratamento para as atividades-fins do Estado, correspondentes a esta ou àquela especialidade técnica, v.g. as relacionadas com a agricultura, indústria, comércio, transportes e comunicações, finanças, segurança, educação, saúde e previdência social. Os técnicos especializados em cada uma das funções assinadas são naturalmente inclinados a pugnar pela primazia na solução dos problemas afetos à sua atividade, sem levar em conta o grau de necessidade com que os mesmos se apresentam no quadro geral das implicações econômico-sociais.

II - Subordinação do Órgão ao Chefe do Poder Executivo, por ser êste o principal responsável pelo funcionamento da máquina administrativa do Estado. De fato, é o mecanismo administrativo que fornece os elementos materiais para a estruturação do plano, e é êsse mesmo mecanismo que se encarrega de sua execução.

Ao Poder Legislativo, como organismo político, incumbe a aprovação ou rejeição do plano no tocante às diretrizes traçadas e às dotações orçamentárias deferidas para a consecução dos objetivos a perseguir.

Ao Poder Judiciário compete velar pelo respeito à ordem jurídica advinda de tais atos. De maneira especial, cumpre ao Tribunal de Contas, em suas funções administrativo-judicantes, exercer o contrôle legal das disposições contidas no plano.

Ai está, perfeitamente caracterizada, a necessária conjugação de esforços entre os três podêres do Estado, para o fim precipuo de defesa do bem-estar social da comunidade, da qual, para isso, recebem delegação expressa da soberania popular.

III - O Órgão deve desempenhar função consultiva e não executiva. Aquela posição (estado-maior, staff) lhe faculta dar maior atenção ao laborioso processo de planejar, isento que fica da pesada carga da função executiva. Com efeito, o planejamento econômico-social é um processo tão complexo, que não deve ser formulado nas horas vagas de um diretor-executivo. Exige técnica especial no equacionamento dos problemas, no levantamento dos dados, na proposição das soluções (princípio da exatidão). São problemas, elementos e soluções que deverão ser trabalhados em função do futuro e não do presente, isto é, visando a resolver situações sem precipitação e não para satisfazer vaidades ou interêsses imediatos, de caráter quase sempre demagógico, de certos políticos e administradores. Trabalho, portanto, que requer do planejador isenção de ânimo e independência fun- 
cional, nem sempre encontradas no agente executor da administração da coisa pública.

Por outro lado, a fusão das duas funções - consultiva e executiva - permitiria viesse o órgão planejador a sofrer descabidas pressões da parte de determinados grupos políticos e econômicos que apresentassem restrições à formulação do planejamento. Porque é muito mais comum do que se pensa, a interferência daqueles elementos no sentido de fazer predominar êste ou aquêle critério orientador, em proveito exclusivo de vantagens partidárias ou econômicas. Interferência que pode provocar até a interrupção do plano (desrespeito ao princípio da continuidade).

A dissociação de competência, proclamada como ideal no exercicio das assinaladas funções, não deve, porém, ir ao ponto de repelir o entrosamento, aliás indispensável, entre planejadores e agentes executivos.

Requisitos exigidos do pessoal - Um dos pontos altos na formulação do planejamento, consiste na qualificação do pessoal para isso recrutado. Qualificação que esteja à altura da importância do empreendimento planejado. Basta atentar para as profundas repercussões que em seu bôjo traz um plano econômicosocial, para avaliar-se o grau de responsabilidade exigido de quem é chamado a elobará-lo. São repercussões que incidirão sôbre milhares e até milhões de criaturas, cujos interêsses sociais c econômicos cumpre resguardar a qualquer título.

Todo profissional especializado deve ser portador de certos atributos técnicos, morais e de inteligência. Para o planejador de empreendimentos econômico-sociais, são considerados atributos preferenciais, entre outros: imaginação fecunda, elevado senso de objetividade, rigor analitico, probidade moral. Imaginação fecundada por um espirito intuitivo, inovador e até mesmo estético; objetividade alicerçada numa percepção aguda dos fatos e valores econômico-sociais, subordinando-os ao primado do interêsse público: rigor analitico na pesquisa dos elementos integrantes dos fatos e fenômenos sócio-econômicos, mediante aplicação do método experimental; probidade moral à prova de quaisquer injunções, sejam elas de caráter íntimo ou provenientes de pressão externa.

Assim credenciado e obediente às normas consubstanciadas no que John Friedmann intitula de Código de Ética (in "Introdução ao Planejamento Democrático"), estará o planejador capacitado a produzir algo de proveitoso no domínio dessa política tão imprescindivel mas ainda pouco compreendida - a planificação econômico-social. 